\title{
Comment 11.1
}

\author{
ANTENOR CESAR VANDERLEI CORREA AND FERNANDA \\ MAGALH Ã E
}

The chapter put into perspective the implementation of policies to support the transfer of knowledge from public research organizations to industry in high- and middle-income countries, drawing on the experience of six countries (Germany, Republic of Korea, the United Kingdom, Brazil, China, and South Africa). Some common traits are identified, although it is made clear that each country requires an individualized analysis of what is needed to build effective knowledge transfer channels between universities and public research institutes and industry.

Our experience in dealing with these issues in Brazil suggests that a set of measures aimed at increasing the "two-way flow" of ideas and people, as identified by the authors, between universities and public research institutes and industry should address three different layers of the problem: cultural, institutional, and financial.

The cultural layer is the most crucial because it deals with the foundation of the system. The limited interaction between the aforementioned actors in middle-income countries is somewhat difficult to overcome. Publishing papers and contributing to the dissemination of knowledge are the main tasks that have been historically associated with universities. Commercial considerations are often seen as a deviation from the purpose of academia. In this context, the relationship with industry is often neglected and sometimes seen as undesirable. One of the problems of not being used to dealing with the industry is related to the protection of knowledge. It is not uncommon for professors involved in applied research to be so keen to show the results of their work that they end up revealing secrets that should be protected. Another element that can add difficulty is the financial incentives normally associated with industry collaboration. Sectors of the university that do not benefit from these incentives in a situation of scarce public funding can produce an environment that is not conducive to commercial dealings. Timing and excessive bureaucracy are other 
issues often mentioned by industry when identifying difficulties in dealing with public research organizations.

The second layer, institutional, is addressed in depth by the authors when they mention the impact of the Bayh-Dole-type legislation on worldwide policies to support the transfer of knowledge from public science. Indeed, the Bayh-Dole Act strongly influenced Brazilian legislation on the matter. The Brazilian Innovation Act from 2004 was the first step toward establishing institutional and legal frameworks to facilitate the process of change in the interplay between universities and public research institutes and industry. Some of the key aspects of this initiative were: (i) it consolidated the legislation in order to provide a more coherent and unambiguous basis on which this interaction could happen, thus helping to positively affect the first layer mentioned in the previous paragraph; (ii) the ownership rights attributed to universities and public research institutes placed greater emphasis on the results of research conducted within these institutions; and (iii) the incentives provided to the institution and researchers involved in projects with industry were important in assisting the establishment of a new pattern of relationships. The Innovation Act has been fully revised and a revamped version was approved in 2016. In fact, there was a thorough and overall revision of all aspects of the national science, technology, and innovation policy in the country, even involving changes in the Brazilian National Constitution, which is referred to as the New Science, Technology, and Innovation Legal Framework. The key aspect of the new legislation in regard to the process of knowledge transfer discussed here is the mandatory requirement for all public research organizations to establish their own innovation policies, whose main focus is exactly knowledge transfer to industry.

The third layer, financial, refers to the lack of funding, not only by the government but mainly by the private sector, to support engagement of universities and public research institutes with industry in $\mathrm{R} \& \mathrm{D}$ projects. This layer is considerably influenced by the previous ones, particularly in middle-income countries where the national innovation systems are less mature. For example, in Brazil, most of the investment in $R \& D$ is made by the public sector (56 percent, according to data from the Brazilian Ministry of Science, Technology, Innovations, and Communications), which emphasizes the need for stronger cooperation between public research organizations and industry in order to accrue more economic benefits for society as whole from this type of investment. Due to the lack of 
tradition of investing in high-risk technology-based ventures, such as startup and spinoff companies, there is a low flow of financial resources between industries and universities and public research institutes. It is also worth mentioning that regulations related to the attribution of responsibilities in case of business failure are harsh in relation to all parties involved, including the investors, which is not particularly encouraging for venture capitalists.

These factors, added to budget constraints, do not create a motivating environment for strong partnerships between industry and public research organizations. One measure that could be taken to foster collaboration would be the provision of additional monetary incentives for companies to interact with public research organizations on top of those that provide general incentives for firms to invest in $R \& D$.

During the analysis, the authors explore the policy interventions adopted by countries to promote an effective knowledge exchange policy. They divide policy interventions into two categories: the supply side, which includes incentives for universities to provide technology to industry, and the demand side, which includes incentives for firms to engage with industry. Regarding these incentives, it is interesting to note in Table 11.3, which shows the types of supporting policy among the selected countries, a trend in high-income countries to provide direct government support and a tendency in middle-income countries to enact legal requirements to implement the activity. In Brazil, both legal measures and governmental funding were used to support the interaction.

Although the current institutional framework in Brazil has evolved significantly in order to bridge the gap between public science and industry, there are still considerable challenges to be overcome. The report produced by the Brazilian government with data from universities and research institutes on the implementation of the Innovation Act shows that some progress has been achieved. Over the years, there has been an increase in knowledge transfer offices, protection of intellectual assets, contracts with industry, and revenue from these contracts. Nevertheless, it is difficult to say that it is a harmonized movement, because the country is vast and full of particularities. Most contracts and revenues from these contracts are concentrated within a small number of institutions. Some factors can be mentioned that favor these institutions: location, type of research developed, tradition in the relationship with industry, good laboratory infrastructure, and open-minded researchers to relate to industry. 
From the institutional point of view, we believe that Brazil has established a comprehensive legal framework on innovation policy. But is that enough? As we have tried to point out, there are barriers that can only be overcome with continuous assessment and adjustment of the policies in place. In this context, the authors provide a good guide to assist in these tasks. 